\title{
EDUCATION AND TRAINING Ten reasons why every junior doctor should spend time working in a remote and rural hospital
}

\author{
Authors: Kevin Fox, ${ }^{A}$ Wendy Corstorphine, ${ }^{\mathrm{B}}$ Jenny Frazer, ${ }^{\mathrm{C}}$ Anna Johnstone, ${ }^{\mathrm{D}}$ Alasdair Miller, ${ }^{\mathrm{E}}$ \\ Neil Shepherd ${ }^{F}$ and Paul Cooper ${ }^{C}$
}

KEYWORDS: Training, rural healthcare

\section{Introduction}

Optimal training of the future workforce is essential if we are to deliver effective healthcare in all situations and circumstances. Doctors will need to have the appropriate knowledge and skills to work in their chosen environment. However, additionally they will need to have contentment, by having made the right career choices, and resilience if they are to avoid burnout, which represents a clear threat to service provision. ${ }^{1,2}$ Undertaking training in a remote and rural environment provides direct relevance for those planning a career in remote and rural medicine. Having spent time working in a remote and rural environment, we have become persuaded of its value as part of all junior doctors' clinical development. Increasingly, junior doctors are seeking to take a break in their training progression, and a remote and rural placement may represent a valuable option with the potential to recruit those doctors to remote and rural practice. ${ }^{3}$

This paper was developed using an iterative conversation with a convenience sample - the junior and senior staff of the Balfour Hospital, NHS Orkney. The hospital serves a population of 25,000 people and visitors of the Orkney Islands, an archipelago off the north coast of Scotland, with no land connection to the mainland. Non-consultant grade staff include early-year junior doctors, hospital practitioners and general practitioner (GP) trainees, but no registrars. Email was used to invite contributions and create a provisional list. This was supplemented with one-toone conversations with junior and senior staff. The ' 10 reasons' were identified and then iteratively revised through further communications and conversations.

Authors: ${ }^{A}$ consultant cardiologist, Imperial College Healthcare NHS Trust, London, UK and consultant physician and cardiologist, Balfour Hospital, Kirkwall, UK; ${ }^{B}$ hospital doctor and education lead, Balfour Hospital, Kirkwall, UK; ' Consultant anaesthetist, Balfour Hospital, Kirkwall, UK; ' trainee doctor, Balfour Hospital, Kirkwall, UK; ${ }^{\mathrm{E}}$ consultant in acute and general medicine, Balfour Hospital,

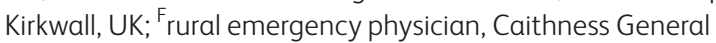
Hospital, Wick, UK

\section{Reasons}

You are exposed to the complete spectrum of medicine

Large and particularly urban hospitals no longer offer a true general medical take. For very good reasons, acute myocardial infarction and stroke are hived off to subspecialty services. ${ }^{4}$ In a wider context, major trauma, oncology, paediatrics and obstetrics are often not co-located with acute medicine. These are understandable but artificial silos and, as a junior doctor, being exposed to the complete spectrum of medicine provides a holistic perspective and a very broad clinical challenge. Everything learnt at medical school (and quite a lot that wasn't) may be needed.

The importance of generalism is being revisited in medical training, not least with the introduction of the 3-year internal medicine training programme, but nowhere can offer better general experience than a small remote or rural hospital. 5,6

\section{You will experience true continuity of care}

Continuity of care is better for learning and better for patient outcomes. Driven by many factors, but certainly by the " 4 -hour wait' rule, larger hospitals now pass patients through several environments during even a short admission. Typically, this also means patients pass through several trainee doctors, each playing a small part in their care pathway. An example would be a patient admitted with diabetic ketoacidosis (DKA) due to missing insulin doses. They receive initial stabilisation in the emergency department (ED), further care on an acute medical unit (AMU) or high dependency unit and then onto a diabetes specialist ward. A trainee in the ED will learn about diagnosis of DKA, the trainee on the AMU will learn about the management and stabilisation of the patient and the return to normal metabolism and insulin therapy, while the trainee on the diabetes ward will learn about understanding factors that precipitate DKA and the importance of patient education in preventing recurrence.

In a small rural hospital, the same doctor will likely receive the phone call from the GP prior to referral and be involved in all stages of their care. The learning is trebled. It's likely the diabetes nurse will have real understanding of the patient's circumstances as they live in the same community. Indeed, they may well see the patient in the high street weeks later perhaps eating an apple or a Mars bar depending on the effectiveness of the education. 
The continuity of care extends to patients with less successful outcomes. The doctors in a rural community will see a funeral advertised in the local flower shop and read an obituary in the local paper, bringing a valuable reality to the ups and downs of a physician's work. ${ }^{7}$

\section{You will have greater responsibility}

While rural hospitals often have highly qualified and experienced nurse practitioners and allied healthcare professionals, the diagnostic and decision-making responsibilities available to trainees are likely to be far greater than in hospitals with large 'take' teams which include middle grades and, increasingly, on-site consultants.

Junior doctors will have to operate outside their comfort zone and learn to seek and use protocols for conditions they are unfamiliar with treating. They will understand the value of guidelines, but also learn to critically appraise them for an individual patient circumstance.

They will learn to possess 'clinical courage. ${ }^{8}$ Clinical courage may be defined as 'that inner debate that we must all have with ourselves, in that space where the needs of our patients and the extent of our training and experience intersect.'

Communication is an essential skill in medicine and 'handovers' are an important part of any trainee's work. But in a rural hospital, trainees must learn to succinctly communicate not just with offsite consultants and distant specialists but also with paramedic transfer teams, lifeboat crews etc.

\section{You will have to think outside the box}

Junior doctors will be involved with situations not listed in any textbook. Care will be affected by geography and weather as well as the limitations of the facilities on offer. Imaging may be limited (there is no magnetic resonance imaging in offshore communities in Scotland). Radiology and pathology staff may be non-resident, so requesting tests requires greater thought as to its immediate impact on the patients' care. Guidelines and the evidence underpinning them may need re-evaluation.

For example, rivaroxaban can cause gastrointestinal bleeding. In large trials it offers benefit for patients with atrial fibrillation (AF) but the trial population probably had faster access to urgent endoscopy and clotting factors - how does that translate to a patient with AF on an island? ${ }^{9}$

You will have greater consultant supervision and closer working relationships

Within a small team, often with no 'middle grades' (typically specialist registrars), the link between the consultant and the junior doctors will be closer and more effective for learning. They will be nurtured because there is a real motivation to train and the time to do it. There is consistency of trainer contact. There is rapid feedback in the training pathway - improvement can be immediately identified and converted to greater responsibility accelerating the learning curve.

Additional opportunities arise; for example tele (video) clinics where a consultant links to the patient and an on-site junior doctor provides the valuable training scenario whereby the junior doctor gets asked to elicit physical signs observed by the remote consultant (classically seen in neurology tele clinics). ${ }^{10}$
You will work closely with hospital managers and other support staff

Introducing an understanding of the administration of the health service and opportunities to undertake quality improvement projects and even leadership roles are being encouraged. While this has been formalised in large hospitals, eg through the chief registrar programme, access to the managerial team can be limited. ${ }^{11}$ In a rural and remote environment, the senior leadership are likely to be much more visible - and probably have lunch in the one small dining room. Contact builds relationships which then facilitate engagement.

\section{You will have time to study for exams}

While far from universally true, generally posts are busy but not overwhelming. Commutes are short and distractions fewer. Rural and remote hospitals face challenges in recruitment that mean they are disposed to applications for study leave.

\section{You will mix with consultants and other junior doctors who have had varied career paths}

Everyone has a story to tell. This is a universal truism, but particularly so in remote and rural hospitals where a distinct career decision has been made by those working there. Learning about their careers can open the eyes of junior doctors to opportunities they had not previously considered. Some will of course be there with a lifetime commitment to rural and remote healthcare. Often the other junior doctors will also have made career choices worth discussing.

But flexible work plans are common, perhaps mixing their rural work with medical practice for charities or in other parts of the world. Foreign experience is frequent among the consultants and often other junior doctors.

\section{You will have time to reflect and consider future career pathways including career breaks}

Perhaps there is a danger of over romanticising. ${ }^{12}$ However, the remoteness and tranquillity of rural healthcare does facilitate reflection. Career choices and work-life balance can be reassessed. With the focus on wellbeing and avoiding burnout, early data suggest benefits of 'a retreat' during training. ${ }^{13}$ It may be a post to undertake before key choices are made, or when a career has hit difficulty, but there are no moments in life where reflection is wasted.

\section{It's hugely enjoyable}

Data are few, partly because these posts are typically not published within the General Medical Council's trainees' survey, but widespread informal feedback suggests rural and remote posts are valued and enjoyed for the work, and for the opportunities to enjoy rural and outdoor life.

\section{Conclusion}

The pressures on the NHS workforce are under scrutiny and plans for a future workforce are a central plank of The NHS Long Term Plan. ${ }^{14}$ If doctors are to be effective, they need to feel motivated and content in their work. A period of time in a remote and rural 
hospital during one's early years is essential for those planning a career in remote and rural practice but, in addition, should be a carefully considered option for all trainees to gain skills and make the right career choices.

\section{Acknowledgements}

The authors would like to thank the clinical and non-clinical staff of the Balfour Hospital for their vital contribution to the preparation of this paper.

\section{References}

1 Rotenstein LS, Torre M, Ramos MA et al. Prevalence of burnout among physicians: A systematic review. JAMA 2018;320:1131-50.

2 Tawfik DS, Scheid A, Profit ] et al. Evidence relating health care provider burnout and quality of care: A systematic review and meta-analysis. Ann Intern Med 2019;171:555-67.

3 UK Foundation Programme Office. F2 Career Destinations Report 2018. UKFPO, 2018. www.foundationprogramme.nhs.uk/sites/default/ files/2019-01/F2\% 20Career \% 20Destinations \% 20Report_FINAL.pdf

4 Keeley EC, Boura JA, Grines CL. Primary angioplasty versus intravenous thrombolytic therapy for acute myocardial infarction: a quantitative review of 23 randomised trials. Lancet 2003;361:13-20.

5 Joint Royal Colleges of Physicians Training Board. Shape of Training and the physician training model. JRCPBT, 2019. www.jrcptb.org. uk/imt
6 Rimmer A. Training the new generalists. BMJ 2019;366:15042.

7 Moores TS, Castle KL, Shaw KL, Stockton MR, Bennett MI. 'Memorable patient deaths': reactions of hospital doctors and their need for support. Med Educ 2007;41:942-6.

8 Wootton J. President's message. Clinical courage. Can J Rural Med 2011;16:45-6.

9 Patel MR, Mahaffey KW, Garg ] et al. Rivaroxaban versus warfarin in nonvalvular atrial fibrillation. N Engl J Med 2011;365:883-91.

10 Patel UK, Malik P, DeMasi M, Lunagariya A, Jani VB. Multidisciplinary approach and outcomes of tele-neurology: A review. Cureus 2019:11:e4410.

11 Royal College of Physicians. Chief registrar scheme. RCP, 2020. www.rcplondon.ac.uk/projects/chief-registrar-scheme

12 Simpson C, McDonald F. Rethinking rural health ethics. Springer, 2017:45-57.

13 Haber MA, Gaviola GC, Mann JR et al. Reducing burnout among radiology trainees: A novel residency retreat curriculum to improve camaraderie and personal wellness -3 strategies for success. current problems in diagnostic radiology. Curr Probl Diagn Radiol [Epub ahead of print].

14 NHS England. The NHS Long Term Plan. London: NHS, 2019.

\section{Address for correspondence: Dr Kevin Fox, Department of} Cardiology, Imperial College Healthcare NHS Trust, Charing Cross Hospital, Fulham Palace Rd, Hammersmith, London W6 8RF, UK. Email: k.fox@imperial.ac.uk

\section{Voices from Shetland}

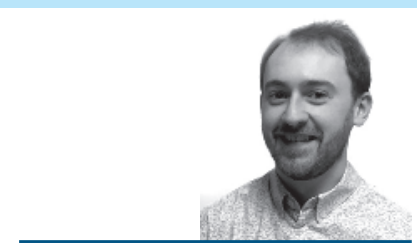

\section{C6}

This is one of the most demanding jobs I have encountered. The hours worked and the responsibility are huge but in Shetland a doctor 'sees' a patient in a holistic way."

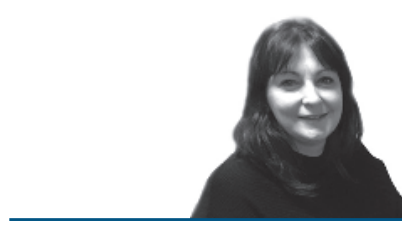

\section{C6}

You know your patients and they often know you and your family. It is a real privilege to both live and work in a remote and rural setting."

- Pauline Wilson, physician

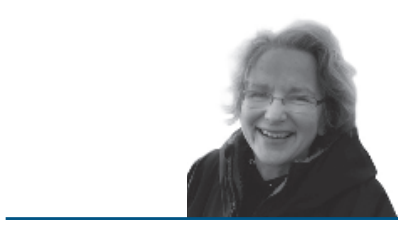

66

There is a sense of team in this hospital, of care from your colleagues, that you just don't find in many places anymore."

- Catriona Barr, anaesthetist

- Cormac Doyle, junior doctor

Shetland has flexible employment opportunities for consultant staff particularly in general medicine, anaesthetics and psychiatry as well as opportunities for junior doctors. For more perspectives from medics on living and working in this remote community, including the highs and the lows, visit www.shb.scot.nhs.uk/board/remote-rural.asp. 